\title{
Pseudoaneurysm formation following a traumatic wrist laceration
}

\author{
Naveen Poonai, MD*; Rodrick Lim, MD*; Tim Lynch, MD*
}

\section{ABSTRACT}

Pseudoaneurysms occur secondary to partial disruption of the arterial wall. They are a commonly described complication of arterial injury, with penetrating injury and iatrogenic arterial catheterization being the most common etiologies in children. Many present weeks to months after the injury, and the initial vascular injury is often missed. The complications of pseudoaneurysm, which include thromboembolism, neurapraxia, and compartment syndrome, underscore the importance of early recognition and management. Definitive therapy consists of ultrasound-guided compression or resection and possible graft interposition. We describe a case of pseudoaneurysm formation in the radial artery of an adolescent girl 6 weeks following a penetrating injury. The patient's injury was complicated by sensory and motor deficits consistent with ulnar nerve compression. This case attests to the importance of adequately ruling out arterial injury in penetrating injury and close followup if the history is suggestive. In addition, a high index of suspicion is warranted to facilitate imaging of a pulsatile mass to avoid confusion of a thrombosed artery with an abscess.

\section{RÉSUMÉ}

Les pseudoanévrismes sont le résultat d'une rupture partielle de la paroi artérielle. C'est une complication couramment décrite de la lésion artérielle, la blessure pénétrante et le cathétérisme artériel iatrogène constituant les étiologies les plus fréquentes chez les enfants. Ils se présentent à l'urgence des semaines, voire des mois après le traumatisme, et la blessure vasculaire initiale n'est souvent pas repérée. Les complications du pseudoanévrisme, dont la thromboembolie, la neurapraxie, et le syndrome des loges, soulignent l'importance du dépistage et de sa prise en charge précoces. La compression échoguidée ou la résection et possiblement l'interposition d'une greffe représentent le traitement définitif. Nous décrivons un cas de pseudoanévrisme dans l'artère radiale d'une adolescente 6 semaines après une blessure pénétrante. La blessure de la patiente a été aggravée par des déficits sensoriels et moteurs compatibles avec une compression du nerf cubital. Ce cas démontre l'importance d'exclure la lésion artérielle en cas de blessure pénétrante et de faire un suivi étroit en présence d'antécédents évocateurs. En outre, un haut degré de suspicion est justifié pour faciliter l'imagerie d'une masse pulsatile afin d'éviter toute confusion entre une artère thrombosée et un abcès.

\section{Keywords: pseudoaneurysm, radial artery}

Pseudoaneurysms are a rare but well-described complication of arterial injury. Many lesions are missed at the time of the initial injury and present months later with increasing pain and swelling at the site of the original wound. Complications such as thromboembolism, infection, neurapraxia, and compartment syndrome have been reported.

Thromboembolism can lead to vascular insufficiency, which highlights the need for early recognition and referral for surgical management. In addition, early imaging serves to differentiate this vascular phenomenon from an abscess, thus avoiding the potential consequence of incision and drainage.

We present the case of a radial artery pseudoaneurym complicated by ulnar nerve compression following a penetrating injury for which vascular integrity was initially documented.

\section{CASE REPORT}

A 16-year-old right-handed girl voluntarily thrust her right hand through a pane of glass. She reported that

From the *Department of Paediatrics, University of Western Ontario, London Health Sciences Centre, Children's Hospital of Western Ontario, London, ON.

Correspondence to: Dr. Naveen Poonai, London Health Sciences Centre, Victoria Hospital, Room E1-110, 800 Commissioners Road East, London, ON N6A 2V5; poonai@hotmail.com.

Submitted Oct. 17, 2009; Revised Nov. 1725 Dec. 17, 2009; Accepted Dec. 19, 2009

This article has been peer reviewed. 
she was impaled by a large piece of glass at the level of the distal wrist crease at the base of the thenar eminence and extending toward the fifth digit. She removed the glass and witnessed a large amount of pulsatile blood emanating from the wound. A pressure dressing was applied, and she was brought to the emergency department (ED) by paramedics.

Her medical history included bipolar disorder treated with lithium and was otherwise unremarkable. She arrived with stable vital signs to the ED. On removal of the pressure dressing, a 2 to $3 \mathrm{~cm}$ laceration to the volar surface of the right wrist was evident, with immediate pulsatile bleeding on extension of the wrist. She had one episode of brief syncope in the ED, which resolved with supine positioning. There were no other injuries. Motor function of the radial, median, and ulnar nerve territories was unimpaired. Two-point discrimination to the finger pads was normal. There was no paresthesia. The ulnar and radial pulses were strong. Light touch sensation to the C6-8 dermatomes was intact distally. The wound was explored by the plastic surgery service, and no evidence of arterial and venous injury was found.

Complete blood count, electrolyte panel, and urea and creatinine levels were within normal limits. A radiograph of the right hand did not reveal any radiopaque foreign bodies or bone or joint abnormalities.

The patient was given $2 \mathrm{mg}$ morphine intravenously and a $1 \mathrm{~L}$ bolus of $0.9 \%$ normal saline following her syncopal episode. The wound was repaired with five interrupted 3-0 polypropylene sutures with no complications. She received tetanus and diphtheria toxoids, $0.5 \mathrm{~mL}$. Removal of sutures was planned in 1 to 2 weeks. She was not placed in a splint.

She returned 15 days later for suture removal. She complained of ongoing pain in the region of the injury, often waking her from sleep, as well as paresthesia to the fourth and fifth digits. ED documentation reported normal wrist range of motion and neurovascular status, and she was discharged from the ED with no further investigations.

The patient returned to the ED 6 weeks later complaining of a 4-day history of pain and diminished sensation to the fourth and fifth digits of the right hand. She recounted that she had decreased strength in her hand, had been dropping objects, and, in particular, had difficulty with the key pinch manoeuvre. She also reported altered hot and cold sensation. She was afebrile at the time, and her vital signs were stable. Finger flexion was intact, as was wrist flexion and extension. Decreased two-point discrimination sensation was appreciated over the fourth and fifth finger pads. A large hematoma was seen on the volar aspect of the wrist. On radiography, no radiopaque foreign body was seen. Ultrasonography of the mass was performed 2 days later showing a complex cystic and solid lesion measuring $26 \mathrm{~mm}$ long, $13 \mathrm{~mm}$ at its shortest axis, and $10 \mathrm{~mm}$ thick, localized over the volar aspect of the hypothenar eminence (Figure 1). The lesion was immediately deep to the volar skin surface and did not affect underlying flexor tendons, intrinsic musculature, or bone. The findings were most consistent with a thrombosed pseudoaneurysm.

The patient was seen 1 week later in the plastic surgery clinic. Physical examination at that time showed what initially appeared to be a well-perfused right hand. Allen testing showed evidence of diminished flow in the ulnar artery compared to the left hand. She had diminished sensation of the volar aspect of the ulnar 1.5 digits. Intraosseous strength was diminished at $4 / 5$. Flexor and extensor tendon function of the fingers was intact. She was booked for magnetic resonance imaging of the hand and an electromyogram study of the ulnar nerve. Unfortunately, the patient never returned for the aforementioned investigations or management and was lost to follow-up at our centre.

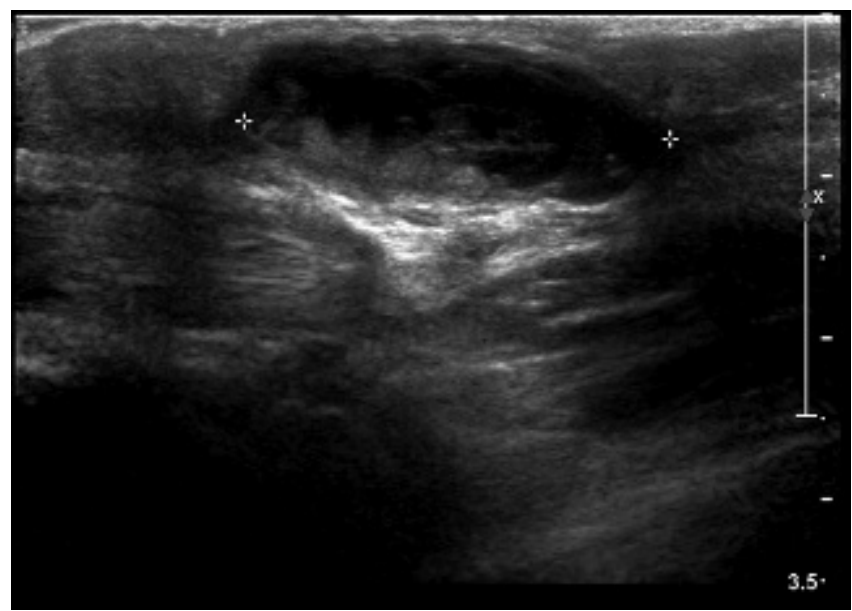

Fig. 1. Ultrasonography scan of the wrist of a 16-year-old girl showing a complex cystic and solid lesion measuring $26 \mathrm{~mm}$ long, $13 \mathrm{~mm}$ at its shortest axis and $10 \mathrm{~mm}$ thick, localized over the volar aspect of the hypothenar eminence. 


\section{DISCUSSION}

Pseudoaneurysms are the result of a partial laceration or incomplete traumatic disruption of the arterial wall that permits blood to escape into the surrounding tissue. A fibrin wall gradually forms around the hematoma. Progressive expansion may take several months. Pseudoaneurysms lack all three layers of the arterial wall, in contrast to a true aneurysm, which is within the intima, media, or adventitia.

Pseudoaneurysms are more common following penetrating injuries but have been described following blunt injury. Although femoral and radial arteries are the most common sites for pseudoaneuryms, ${ }^{1}$ many sites and mechanisms of pseudoaneurysmal formation have been described. Overall, pseudoaneurysms are most often observed in the groin after coronary artery catheterization. ${ }^{2}$ Other common antecedents include arteriovenous shunting for dialysis, placement of indwelling catheterization, and arterial puncture for blood gas analysis. ${ }^{2}$

Risk factors for pseudoaneurym formation include the use of anticoagulants or antiplatelet drugs. ${ }^{1}$ In addition, underlying pathology such as high origin of the radial artery, ${ }^{3}$ hemophilia $\mathrm{A},{ }^{4,5}$ neurofibromatosis, ${ }^{6}$ and Behçet syndrome ${ }^{7}$ may predispose to pseudoaneurysm formation.

With respect to radial pseudoaneurysms in children, the most common cause is arterial catheterization, ${ }^{2}$ and the most frequently involved vessel is the femoral artery. ${ }^{8}$ There are no data to suggest that the incidence of pseudoaneuryms is epidemiologically skewed based on age. In contrast to adults, however, vascular injuries in children pose unique problems such as the possible complications of tissue loss and growth discrepancy secondary to arterial ischemia and arteriovenous fistulae. $^{8}$

Many of these lesions occur as a result of missed injury at the time of presentation. They have been reported to present months to years after the initial injury. In a comprehensive review, Rich and colleagues noted that $47 \%$ of these lesions present after 30 days. ${ }^{9}$ The incidence of pseudoaneurysms is unknown, likely because they are seldom reported or go unrecognized. ${ }^{10}$

The natural history of pseudoaneuryms is also unknown; however, complications such as neurapraxia, ${ }^{11,12}$ compartment syndrome, ${ }^{13}$ rupture, and hemorrhage ${ }^{14}$ have been described. Thromboembolism can lead to gangrene and amputation, which underscores the need for early recognition and surgical management.
History and physical examination are often sufficient to make a diagnosis. Generally, the patient will present with a pulsatile mass several weeks to months after an inciting injury. A history consistent with arterial bleeding is usually reliable. Pain and erythema may be present, and paresthesia is common as the mass subtends an adjacent nerve. Compression of the artery proximal to the mass should diminish the pulsations. A bruit may be present. Yetkin and Gurbuz described nine cases of posttraumatic brachial artery pseudoaneurysm following penetrating injury. ${ }^{15}$ In all cases, a pulsatile mass was appreciated with digital examination. Angiography has traditionally been the gold standard imaging modality; however, colour flow Doppler ultrasonography is the preferred method of diagnosis because it is accurate, noninvasive, and readily available and does not require contrast or radiation. ${ }^{2}$ Doppler ultrasonography should demonstrate turbulent flow and vessel dilatation. Early imaging is important given the possibility of the disastrous consequence of incision and drainage should the mass be confused with an abscess.

Treatment of pseudoaneurysms includes bandage, ultrasound-guided manual compression, ligation, endovascular graft implantation, embolization, ultrasound-guided thrombin injection, and resection followed by end-to-end anastomosis. Ultrasound-guided compression has replaced surgical revision owing to its low rate of complications and high rate of success (83$95 \%)^{16}$; however, the success rate is still lower than that of operative intervention. Given the high recurrence rate in anticoagulated patients and the need for sedation and analgesia, ultrasound-guided compression has yielded to ultrasound-guided intra-aneurysmal thrombin injection as a preferred modality in some clinical situations. The technique of ultrasound-guided compression involves directly applying manual pressure with the ultrasound probe sufficient to impede arterial flow to the pseudoaneurysm at regular intervals. Compression is deemed successful when the absence of flow or the presence of a thrombus is confirmed by colour flow imaging. ${ }^{16}$ Although painful, time-consuming, and difficult when used on large pseudoaneurysms, the technique has a high success rate. ${ }^{17}$ However, there are no reports of the successful employment of ultrasound-guided compression obliteration in children. ${ }^{18}$ Ultrasound-guided thrombin injection also has been reported to have a high success rate (92-100\%) even among patients taking 
anticoagulants. ${ }^{19}$ Despite reported complications such as thromboembolism ${ }^{20}$ and anaphylaxis, ${ }^{21}$ this modality is becoming the method of choice for treatment of simple pseudoaneurysms. ${ }^{19}$ Unlike ultrasound-guided compression, thrombin injection has been reported to be safe and effective in pediatric patients. ${ }^{17,22,23}$

Experience is limited in the conservative management of pseudoaneurysms of the radial artery in children. ${ }^{10}$ Operative intervention has been described in various locations of pseudoaneuryms but may be complicated by growth retardation because of inadequate blood flow. Surgery is often reserved for expanding, actively bleeding, or otherwise complicated lesions. ${ }^{10}$ Zitsman described a radial artery pseudoaneurysm among four cases of pseudoaneurysm in children and adolescents following lacerations. ${ }^{24}$ All cases were successfully managed with resection of the pseudoaneurysm and ligation of the feeding arteries.

Although the development of pseudoaneurym following arterial injury is uncommon, complications are well described. These include thromboembolism, nerve compression, hemorrhage, and even compartment syndrome. ${ }^{11-14}$ Although our patient was lost to follow-up, the objective in presenting this case is to highlight several issues paramount to the recognition of pseudoaneurysm and prevention of its complications.

First, deep wounds should be explored for arterial injury. In our patient, the development of a pseudoaneurym despite documentation of vascular integrity at the time of injury was due to either incomplete visualization of the radial artery or the presence of a vascular injury too small to be seen. The presence of a voluminous pulse distal to the site of injury may not reliably exclude vascular interruption. If a history consistent with arterial injury is obtained, yet no evidence of such is found, close follow-up is crucial.

Second, clinicians should have a high index of suspicion for pseudoaneurysm in a case of a warm, fluctuant, erythematous posttraumatic mass presenting weeks to months following injury and located in close proximity to the site of a penetrating or blunt injury. Colour Doppler ultrasonography should be arranged, and the results should be used to plan a possible medical or surgical intervention. Masses should be examined for signs of infection and pulsatility. In the affected limb, paresthesia and evidence of distal ischemia should be ruled out.

\section{CONCLUSION}

Pseudoaneurym is a rare but potentially serious complication of arterial injury that can lead to infection, nerve compression, or thromboembolism. Late presentations are common and can easily be overlooked or confused with other pathologies. Given the potential sequelae of an expanding space-occupying lesion in a muscle compartment, a high index of suspicion and early imaging with colour flow Doppler ultrasonography are essential to plan for definitive management.

Competing interests: None declared.

\section{REFERENCES}

1. Gudena R, Khetan N. Swelling of volar aspect of the wrist. Postgrad Med 7 2005;81:e9, e11.

2. Levis JT, Garmel GM. Radial artery pseudoaneurysm formation after cat bite to the wrist. Ann Emerg Med 2008; 51:668-70.

3. Noguchi M, Hazama S, Tsukasaki S, et al. Iatrogenic pseudoaneurysm in a hemodialysis patient: the hidden hazard of a high radial artery origin. Heart Vessels 2004;19: 98-100.

4. Harkin DW, Connolly D, Chandrasekar R, et al. Radial artery mycotic pseudoaneurysm in a haemophiliac: a potentially fatal complication of arterial catheterization. Haemophilia 2002;8:721-4.

5. Fields JM, Saluja S, Schwartz DS, et al. Hemophilia presenting in an infant as a radial artery pseudoaneurysm following arterial puncture. Pediatr Radiol 1997;27:763-4.

6. Singh S, Riaz M, Wilmshurst A, et al. Radial artery aneurysm in a case of neurofibromatosis. Br 7 Plast Surg 1998;51:564-5.

7. Reus M, Vásquez V, Alonso J, et al. Treatment of a radial artery pseudoaneurysm with ultrasond-guided percutaneous thrombin injection in a patient with Behçet's syndrome. 7 Clin Ultrasound 2003;31:440-4.

8. Dzepina I, Unusic J, Mijatovic D, et al. Pseudoaneurysms of the branchial artery following venipuncture in infants. Pediatr Surg Int 2004;20:594-7.

9. Rich NM, Hobson RW 2nd, Collins GJ Jr. Traumatic arteriovenous fistulas and false aneurysms: a review of 558 lesions. Surgery 1975;78:817-28.

10. Cozzi D, Morini F, Casati A, et al. Radial artery pseudoaneurysm successfully treated by compression bandage. Arch Dis Child 2003;88:165-6.

11. Robbs JV, Naidoo KS. Nerve compression injuries due to traumatic false aneurysm. Ann Surg 1984;200:80-2.

12. Yilmaz AT, Arslan M, Demirkiliç U, et al. Missed arterial injuries in military patients. Am $\mathcal{F}$ Surg 1997;173:110-4.

13. Rimoldi RL, Gogan WJ, Koulisis CW, et al. Pseudoaneurysm of the radial artery as a cause of a late 
compartment syndrome. Clin Orthop Relat Res 1990;251: 263-5.

14. Ganchi PA, Wilhelmi BJ, Fujita K, et al. Ruptured pseudoaneurysm complicating an infected radial artery catheter: case report and review of the literature. Ann Plast Surg 2001;46:647-50.

15. Yetkin U, Gurbuz A. Post-traumatic pseudoaneurysm of the brachial artery and its surgical treatment. Tex Heart Inst 7 2003;30:293-7.

16. Hajarizadeh H, LaRosa C, Cardullo P, et al. Ultrasoundguided compression of iatrogenic femoral pseudoaneurysm failure, recurrence, and long-term results. $\mathcal{F}$ Vasc Surg 1995; 22:425-30.

17. Pelchovitz DJ, Cahill AM, Baskin KM, et al. Pseudoaneurysm in children: diagnosis and interventional management. Pediatr Radiol 2005;35:434-9.

18. Landau D, Schreiber R, Szendro G, et al. Brachial artery pseudoaneurysm in a premature infant. Arch Dis Child Fetal Neonatal Ed 2003;88:F152-3.
19. Krueger K, Zaehringer M, Strohe D, et al. Postcatheterization pseudoaneurysms: results of US-guided percutaneous thrombin injection in 240 patients. Radiology 2005;236:1104-10.

20. Lennox A, Griffin M, Nicolaides A, et al. Regarding percutaneous ultrasound guided thrombin injection: a new method for treating post-catheterization femoral pseudoaneurysms. 7 Vasc Surg 1998;28:1120-1.

21. Elford J, Burrell C, Freeman S, et al. Human thrombin injection for the percutaneous treatment of iatrogenic pseudoaneurysms. Cardiovasc Intervent Radiol 2002;25:115-8.

22. Frush DP, Paulson EK, O'Laughlin MP. Successful sonographically guided thrombin injection in an infant with a femoral artery pseudoaneurysm. AfR Am 7 Roentgenol 2000;175:485-7.

23. Pezzullo JA, Wallach MT. Successful percutaneous thrombin injection of a brachial artery pseudoaneurysm in a neonate. A7R Am 7 Roentgenol 2002;178:244-5.

24. Zitsman JL. Pseudoaneurysm after penetrating trauma in children and adolescents. $\mathcal{F}$ Pediatr Surg 1998;33:1574-7. 